\title{
"Nihilism" of chronic heart failure therapy in children and why effective therapy is withheld
}

\author{
Dietmar Schranz $^{1} \cdot{\text { Norbert F. } \text { Voelkel }^{2}}^{2}$
}

Received: 17 August 2015 / Revised: 6 December 2015 / Accepted: 26 January 2016 / Published online: 19 February 2016

(C) The Author(s) 2016. This article is published with open access at Springerlink.com

\begin{abstract}
Major advances in chronic heart failure (cHF) therapy have been achieved and documented in adult patients, while research regarding the mechanisms and therapy of cHF in children has lagged behind. Based on receptor physiological studies and pharmacological knowledge, treatment with specific $ß 1$-adrenergic receptor blocker (ARB), tissue angiotensin-converting enzyme inhibitor (ACE-I), and mineralocorticoid antagonists have to be recommended in children despite lack of sufficient data derived from prospective randomized studies. At our institution, bisoprolol, lisinopril, and spironolactone have been firmly established to treat systolic $\mathrm{cHF}$, hypoplastic left heart syndrome (HLHS) following hybrid approach and congenital left-right shunt diseases, latest in patients where surgery has to be delayed. Chronic therapy with long-acting diuretics and fluid restriction are not advocated because short-term effects are achieved at the expense of further neuro-humoral stimulation. It remains unclear why diuretics are recommended although evidence-based studies, documenting long-term benefit, are missing. However, that is true for all currently used drugs for pediatric cHF.
\end{abstract}

Communicated by Jaan Toelen

Electronic supplementary material The online version of this article (doi:10.1007/s00431-016-2700-3) contains supplementary material, which is available to authorized users.

Dietmar Schranz

dietmar.schranz@paediat.med.uni-giessen.de

Norbert F. Voelkel

nvoelkel@vcu.edu

1 Pediatric Heart Center, Justus-Liebig University Clinic, Feulgenstr. 12, 30385 Giessen, Germany

2 School of Pharmacy, Virginia Commonwealth University, Richmond, VA, USA
Conclusion: This review focuses on the prevailing "nihilism" of cHF therapy in children with the goal to encourage physicians to treat pediatric cHF with a rationally designed therapy, which combines available agents that have been shown to improve survival in adult patients with cHF. Because of the lack of clinical trials, which generate the needed evidence, surrogate variables like heart and respiratory rate, weight gain, image-derived data, and biomarkers should be monitored and used instead. The recommended pharmacological therapy for systolic heart failure is also provided as the basis for utilizing reversible pulmonary arterial banding $(\mathrm{PAB})$ as a novel strategy in young children with dilative cardiomyopathy (DCM) with preserved right ventricular function.

\section{What is Known:}

- Heart failure (HF) in children is a serious public health concern.

- HF has numerous etiologies, but unspecific symptoms.

- HF interplays among neuro-humoral, and molecular abnormalities.

- Pediatric cHF-therapy is currently based on loop-diuretics, fluid restriction and digoxin.

What is New:

- Cardiac function analysis has to include cardiac synchrony and VVI.

- Considering enormous potential of cardiac regeneration, therapy has to extend with selective $\beta 1-A R B$, tissue ACE-I and mineralocorticoid blockers, loop-diuretics avoided as ever possible.

- Inhibition of the endogenous neuro-humoral stimulation is monitored by surrogate parameters as heart and breath rate and systolic and diastolic blood pressure.

- Advocated HF therapy serves for regenerative strategies as reversible Pulmonary Artery Banding in DCM.

Keywords Chronic heart failure · Infants and children . Bisoprolol $\cdot$ Lisinopril $\cdot$ Spironolactone $\cdot$ Pulmonary artery banding 


$\begin{array}{ll}\text { Abbreviations } \\ \text { ACE-I } & \text { Angiotensin-converting enzyme inhibitor } \\ \text { ARB } & \text { Adrenergic receptor blocker } \\ \text { BAR } & \text { B-Adrenergic receptor } \\ \text { BNP } & \text { Brain natriuretic peptide } \\ \text { cHF } & \text { Chronic heart failure } \\ \text { CHF } & \text { Congestive heart failure } \\ \text { DCM } & \text { Dilative cardiomyopathy } \\ \text { HFpEF } & \text { Heart failure with preserved ejection fraction } \\ \text { HLHS } & \text { Hypoplastic left heart syndrome } \\ \text { HTX } & \text { Heart transplantation } \\ \text { LV } & \text { Left ventricle } \\ \text { NO } & \text { Nitric oxide } \\ \text { NYHA } & \text { New York Heart Association } \\ \text { RAA-S } & \text { Renin-angiotensin-aldosterone system } \\ \text { RV } & \text { Right ventricle } \\ \text { VSD } & \text { Ventricle septum defect } \\ \text { VVI } & \text { Ventricular-ventricular interaction }\end{array}$

\section{Considerations}

\section{"Science is neither dogmatic nor democratic!"}

Heart failure is the final stage of a wide variety of cardiac diseases. Symptoms of HF develop, once the heart becomes unable to meet the metabolic demands of the body.

In adults, heart failure is frequently called the new epidemic of the twenty-first century [36]. Causes of heart failure in childhood are associated to congenital heart diseases, cardiomyopathies, and arrhythmias as well as acquired heart and circulatory diseases [21]. Epidemiological studies covering the pediatric age group are very rare. More than 20 years ago, Rodeheffer et al. [46] reported an incidence of four infants $<1$ year of age in 1000 person years and a prevalence in children $<10$ years of age of 1.3 in 1000 .

Hsu and Pearson summarized the various causes of pediatric heart failure [21] as well as the current treatment and future directions [22].

Considering that cardiac output (flow) is based on heart rate, myocardial contractility, preload, afterload, synchrony, and ventricular-ventricular interaction (VVI), a low cardiac output might be associated with heart failure due to one or all of these variables (Fig. 1).

If there is no successful strategy to remove the root cause, the aims of chronic congestive heart failure ( $\mathrm{CHF}$ ) therapy are to modify the neuroendocrine responses that worsen $\mathrm{CHF}$ and their pathophysiological consequences and to stimulate endogenous repair mechanisms.

Established therapies in adults aim at reducing preload, afterload, and neuro-humoral activation and to halt the ongoing loss of cardiomyocytes, which gives way to replacement fibrosis [7]. In Table 1, therapeutic goals for chronic HF treatment in children are summarized.

In this context, tachy- and brady-arrhythmias need to be prevented and if present effectively treated; sinus rhythm heart rate needs to be adjusted to the lowest effective level in order to reduce myocardial oxygen demand and to optimize the diastolic ventricular filling time. Chronic stimulation of a dysfunctional myocardium is counterproductive; all exogenous therapeutic strategies that stimulate the neuro-humoral system have been repeatedly analyzed and ought to be, whenever possible, omitted (for example: chronic treatment with loop-diuretics); if inotropic agents and vasoconstrictors become necessary, they should be used as short as possible or as a bridge towards heart transplant, if cardiac assist devices are not the better option.

Considering the balance of oxygen delivery and consumption, positive inotrope vasodilators (milrinone, levosimendane) ought to be preferentially used as long as myocardial perfusion pressures are not compromised. During catecholamine infusion therapy, strategies designed to protect the myocardium should be considered, for example: a combination of epinephrine or norepinephrine infusion with B1-receptor blockers. In decompensated systolic heart failure, which often occurs in infants and children with dilated cardiomyopathy, short-term epinephrine infusion combined with intravenous or oral ß1-receptor blocking agents (metoprolol, bisoprolol) is not a contradiction, but an actually used and recommended strategy [43]. In addition, it has to emphasize that the right and left heart does not act in isolation; cardiac re-synchronization [35] as well as strategies to improve the ventricular-ventricular interaction (VVI) is desirable in order to allow endogenous cardiac repair, in particular in younger patients $[53,61]$.

Bridging to heart transplantation (HTX), with or without the use of assist devices, or transiting the patient from an acute to a chronic heart failure status might be the therapeutically strategy of choice, if no satisfactory return to normal function can be achieved [53].

\section{Differences of chronic HF treatment in children and adults}

Age- and perhaps mechanism-independent chronic HF is associated with neuro-humoral activation and increased levels of circulating neuro-hormones (noradrenaline, adrenaline, renin, angiotensin II, aldosterone, vasopressin), which lead to vasoconstriction, sodium, and water retention. Continuous endogenous neuro-humoral activation leads to myocardiocyte apoptosis, necrosis, and cardiac fibrosis, the main causes of chamber dilatation and progressive dysfunction, culminating in a vicious cycle of ever worse quality of myocardium and heart function [51].

Medical treatment recommendations for chronic HF in adults have been based on controlled, randomized studies [29]. Large cohort studies were necessary to pinpoint that among a group of 
Fig. 1 Parameters responsible for cardiac output. In addition to heart rate, contractility, preload, and afterload, cardiac synchrony as well as ventricular-ventricular interaction (VVI) defines cardiac function. $\mathrm{CaO} 2$ oxygen content, $\mathrm{Ca}-\mathrm{vDO} 2$ arterial-venous oxygen content difference, $C O$ cardiac output, $D O 2$ oxygen delivery, $H R$ heart rate, $\mathrm{SaO} 2$ arterial oxygen saturation, $\mathrm{SvO} 2$ venous oxygen saturation in superior and inferior caval vein, $S V$ stroke volume, VO2 oxygen consumption

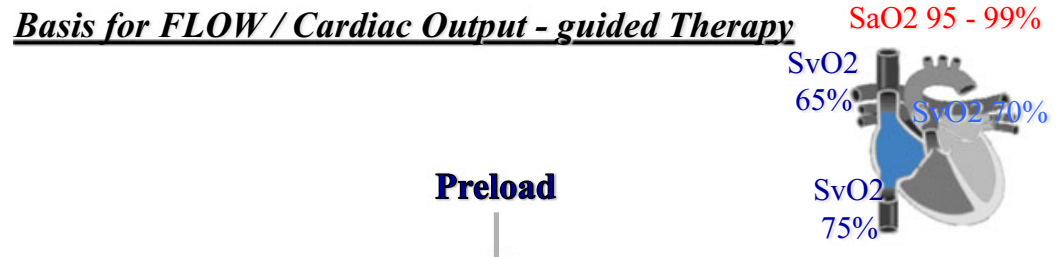

Heart rate Symehromy
HF treatment drugs as $\beta$-adrenergic receptor blockers [2, 3, 40], angiotensin-converting enzyme (ACE) inhibitors [1] and aldosterone receptor antagonists [41] significantly reduce the mortality by counteracting the neuro-humoral overdrive of chronic HF. Such large cohort clinical trials cannot realistically be conducted in children with chronic heart failure due to the small patient numbers and the heterogeneity of the HF causes. Clinical trials in the pediatric age group are generally underpowered and cannot detect significant impact differences on survival rates. Several review articles address the differences in responses to medications in relation to the age of patients, pharmacokinetic/ pharmacodynamic characteristics, and underlying causes of $\mathrm{CHF}$ and their molecular characteristics [48, 51]; however, the overall strategy to block the neuro-humoral axis is not disputed. Rossano and Shaddy [48] pointed to the missing data in children and emphasized that extrapolating evidence from adult patients to children with heart failure may have limited utility. However, given the state of our current situation of pediatric heart failure therapy, this statement lacks a forward-looking attitude and encourages a not-justified therapeutic "nihilism" when it comes to chronic HF treatment in children. Unfortunately, this entirely uncreative state of the affairs has been cultivated over decades [49].

In adults with chronic HF, new therapeutic strategies like angiotensin-neprilysin inhibition have been lauded as a paradigm shift in HF therapy [30], while in children, the use of ACE inhibitors, $ß$-adrenergic receptor blockers, and mineralocorticoid-receptor blockers still remains controversial and - if recommended - is rarely used [60]. This then begs the question, why effective therapy is being withheld in infants and children despite well-designed and sufficiently powered randomized trials in adults, which have been published more than a decade ago? In fact, drugs shown to be highly effective in adult heart failure patients have been discredited because of their use in studies with an unfortunate design, despite or because of their administration in controlled, randomized, double-blind trials which are acknowledged as the gold standard in evidencebased medicine. In one single controlled randomized study, the ACE inhibitor enalapril was judged to be not effective for the treatment of univentricular heart failure [23]; this study has been frequently cited to support the notion that ACE inhibitors are illadvised in the treatment of all children with HF. B-Adrenergic receptor (BAR) blockers have also been labeled to be of no benefit for children with chronic HF; the potential use of highly selective or non-specific BAR blocker has not been considered. In one, highly cited BAR-blocker study in children, the effect of carvedilol was assessed in 106 patients, while placebo was administered to 54 children with functional classes II and III [56]. This study, performed in 26 North American pediatric heart centers, was not stratified according to the causes and severity of HF and terminated after 5 years; in addition, there was no control for co-medications; the dosage of diuretic drugs and whether the BAR-blocker dose was adequate had not been or monitored by simply observing the heart rate response. Remarkably, during the same time period in US pediatric heart centers, BAR blockers were routinely used only in $4 \%$ of children with cHF [60]. This fact illustrates what little clinical experience there is with BARblocker therapy in children with $\mathrm{cHF}$.

Table 1 Therapeutic goals for chronic HF treatment in children

1. Preload optimization by avoiding intravascular, in particular intraarterial, volume depletion

2. Reduction of the systemic vascular resistance without jeopardizing the coronary perfusion pressure

3. Optimizing myocardial oxygen consumption and re-establishing myocardial synchrony as well as VVI

4. Allowing time to establish endogenous and exogenous repair mechanisms 
The third thrust of HF therapy should decrease the endogenous neuro-hormonal response by mineralocorticoid antagonism. In the RALES trial [41], treatment with spironolactone, in addition to conventional therapy, led to a relative reduction of the risk of death by $30 \%$ and of cHF-related hospitalizations by $35 \%$ in adults. In pediatric patients, spironolactone is a common component of diuretic regimens due to its potassiumsparing property but seldom used as a tissue aldosterone antagonist to influence cardiac re-remodeling, in particular myocardial fibrosis. The Canadian guideline reports that therapy with drugs that block the effects of aldosterone is well established in adults with systolic HF; "data regarding the role of spironolactone or related agents in the treatment of children with $\mathrm{cHF}$ are very limited" [25]. However, the few pediatric data published by Masutani et al. - with a focus on the importance of aldosterone-blocking drugs like spironolactone in children with $\mathrm{HF}$, and in particular with preserved ejection fraction (HFpEF), have been widely ignored [28]. On the other hand, since 1978, Engle et al. [16] had administered 137 courses of furosemide to 106 hospitalized pediatric patients with salt and water retention associated with cardiac or renal disease; furosemide is by far the most commonly used and recommended drug, not only for acute but also for chronic heart failure in children. The diuretics are recommended as effective and safe in the pediatric age group when administered acutely as a parenteral medication and over a long-term course by the oral route in the doses and at the time intervals used in this study [16]. Yet, despite a lack of evidencebased studies, the use of diuretics is supported by Cochrane's systematic review [18] as sufficient for the routine use in children with chronic CHF. While there is a recognized lack of evidence with regard to the use of ACE inhibitors, BAR blockers, and mineralocorticoid antagonists in pediatric patients, the chronic use of diuretics has never been scrutinized by pediatric opinion leaders [25]. A similar situation prevails with regard to digoxin treatment of chronic heart failure in infants and children. Again, a randomized, placebo controlled study is only available for adult patients with ischemic or cardiomyopathic CHF. Digoxin had shown weak, but positive effects on left ventricular ejection fraction (EF), exercise capacity, quality of life, and reduction of hospitalizations, but the survival rate in the whole cohort was not significantly improved [14]. In the pediatric literature, we find several early clinical observational studies, which demonstrated a beneficial effect on CHF, including improved contractility and a decreased neuro-hormonal stimulation. Perhaps the $\mathrm{Na} / \mathrm{K}$ ATPase inhibitor digoxin, as a positive inotropic drug might be indicated in younger patients. On the other hand, a recently published study of 48 infants with chronic HF secondary to left-toright shunt lesions who were randomized to treatment with enalapril and furosemide \pm , digoxin did not find any clinical improvement. It was concluded that digoxin does not provide any extra benefit in the treatment of such patients [15]. In considering the results of this latter study, the Canadian guidelines for pediatric chronic HF did not recommend digoxin in children with chronic
HF [25]. However, digoxin is a weak vasoconstrictor and cotherapy with a neuro-hormonal axis-stimulating diuretic is from our point of view not indicated for HF due to a left-right shunt because the shunt flow is favored.

In conclusion: HF drugs need a clearly defined indication and a convincing rationale. Simply, a randomized, placebo controlled study design — which is highly desirable - however, lacking a crisp definition of the clinical target and the underlying disease mechanism does not allow us to generate the needed outcome information. One wonders also why the effectiveness of a chronic HF drug is not reported, as it is customary for the drugs targeting pulmonary arterial hypertension [29]; i.e., if the drug does not significantly alter the mortality, then surrogate endpoints which demonstrate improvement of the clinical status should be obtained to support their use. $\mathrm{PH}$ targeting drugs are not being withheld if they do not affect mortality but improve the clinical functional class $[26,61]$.

\section{Recommendations to improve chronic HF treatment in infants and children}

\section{Systolic dysfunction related to left ventricular dilated cardiomyopathy}

The incidence of childhood cardiomyopathy is in the range of 1.13-1.24 per 100,000 children according to the data collected by two population-based registries, where dilated cardiomyopathy accounts for more than half of the primary causes [6, 27]. Dilated cardiomyopathy (DCM) is a serious disease. The 1-year and 5-year rates of death or transplantation were first described to be 35 and $49 \%$, respectively, in a population-based study in 1998 and 31 and $46 \%$ in the largest population study in 2006 $[39,56]$. Recently, we described in a single-center study a lower rate for death of $18 \%$ and transplantation $31 \%$ [50], which is perhaps the result of an improved treatment strategy (Fig. 2). While the overall goal of the treatment of children with DCM is to avoid death or delay heart transplantation, different survival rates after the diagnosis of DCM may be attributed to different treatment strategies. Prior to treatment, a detailed diagnostic workup is needed for left ventricular (LV)-DCM: this includes the medical history, clinical examination, echocardiogram, Xray, MRI, coronary-angiography, and myocardial biopsy, as well as laboratory data (BNP or NT-proBNP, CRP, hemoglobin, sodium, potassium, creatinin, albumin, and if possible, plasma levels of aldosterone, norepinephrine, angiotensin, renin, respectively). Treatment success is monitored by the clinical functional (NYHA, Ross I-IV) and nutritional status, heart and respiratory rate, intermittent diastolic and systolic blood pressure, and $\mathrm{SaO}_{2}$ measurements. Follow-up laboratory and imaging data should be acquired.

Taking into account-specific exclusion criteria, at our institution, the chronic, age-independent heart failure therapy consists 
Fig. 2 Estimated survival and freedom of death in children with DCM [50]. Shown is the median follow-up 16 months (range 280 months) of 38 children in an age less than 3 years admitted at the Pediatric Heart Center Giessen. The Kaplan-Meier survival curve after the diagnosis of dilated cardiomyopathy revealed a 1-year survival of $97 \%$ and a 5year survival of $86 \%$ [50]

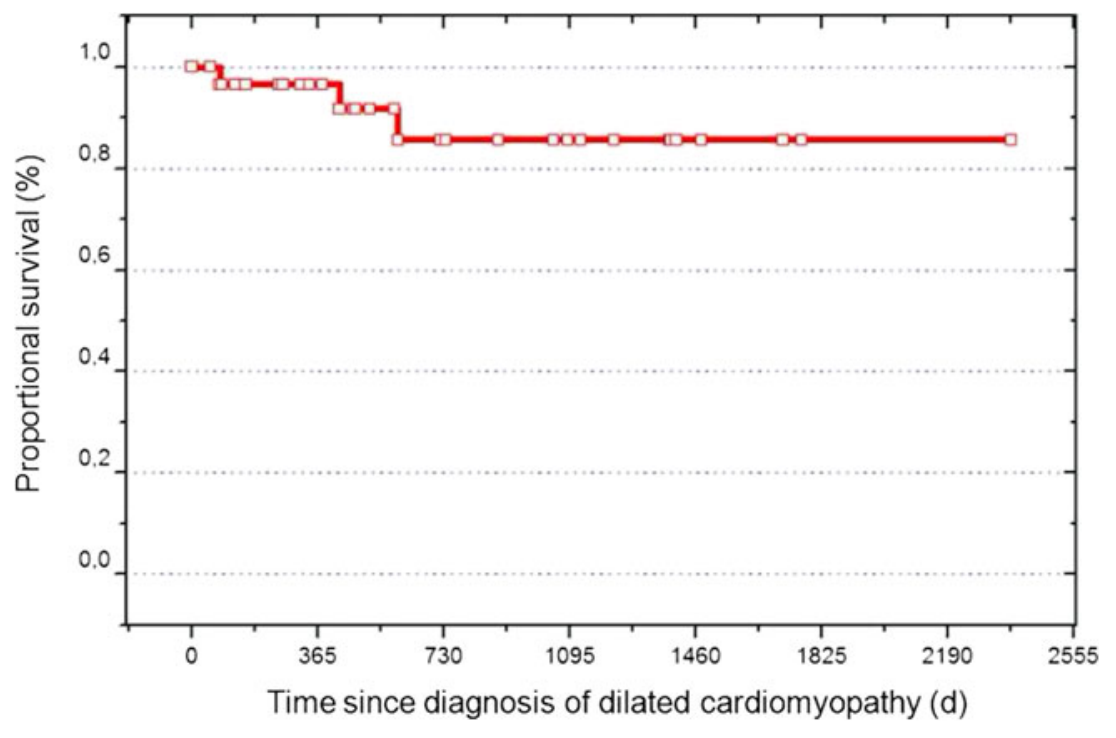

of specific long-acting ß1-adrenoreceptor blocker (bisoprolol), long-acting tissue angiotensin-converting enzyme inhibitor (lisinopril), and mineralocorticoid-receptor blocker (spironolactone) and applying a goal-oriented drug dosage [43]. Digoxin is the fourth-line HF drug with a target of a plasma level of $0.5-0.9 \mathrm{ng} / \mathrm{ml}$. Chronic treatments with loop-diuretics are avoided, and hydrochloro-thiazide in low dosages of $0.5-1 \mathrm{mg} /$ $\mathrm{kg}$ are applied once or twice per day, if really needed. If there are signs of inappropriate ADH secretion with severe hyponatremia, we currently use the V2-receptor antagonist, tolvaptan, once per day in a dosage of $0.1-(0.3) \mathrm{mg} / \mathrm{kg}$, targeting a sodium serum level of 140-145 mmol/l. The hypothesized treatment goals for treatment of LV-DCM with a highly specific 31 -BAR blocker, tissue ACE inhibitor, and aldosterone-antagonist are summarized in Table 2.

Considering the (patho-)physiology of the $\beta$-adrenergic receptors ( $(-\mathrm{AR}$ ) in pediatric DCM, highly selective $\beta 1$-AR blockers are recommended in children to treat chronic HF caused by LVDCM $[34,43,50]$. It is generally accepted that chronic stimulation of the cardiac $\beta 1$-adrenergic system is toxic to the heart and contributes to the pathogenesis of congestive heart failure [11]. We could show that children that underwent open heart surgery with cardiac arrest demonstrated a decreased B-adrenoceptor-mediated adenylate cyclase activation in a manner compatible with an uncoupling of $B$-adrenoceptors from the Gs-protein-adenylate cyclase complex [52]. Cardiac arrest and HF liberate myocardially stored norepinephrine [47] and cause B1-receptor desensitization. As stated, chronic stimulation of $\beta 1$-receptors is cardiotoxic while $\beta 2$-receptor stimulation might be cardioprotective $[8,11]$. The elegant study of Miyamoto et al. [33, 34] not only demonstrated the differences of BAR pathophysiology between pediatric and adult patients with idiopathic dilated cardiomyopathy but also recommended the use of ß1-selective BAR blocker in children. The data by Miyamoto et al. might also explain the failure of non-specific $\beta$-blocking therapy in previous clinical pediatric HF trials. Miyamoto et al. showed that ß1-ARs are downregulated in both adults and children with chronic HF but that the B2-AR is downregulated only in pediatric DCM. She stated "Further inhibition of the already downregulated B2-ARs may override the benefit of B1-AR inhibitor therapy, because preservation of $B 2$-AR function is beneficial." In addition, several studies support the cardio-protective effect of short-term beta-2 stimulation [4, 5, 9, 17, 31, 32, 38, 45, 63]. Bisoprolol is a long-acting, highly cardio-selective BAR-blocker, with a low side effect profile. Bisoprolol has a beta1/beta2-specific binding ratio of about 125 , metoprolol of about 80 , and propranolol and carvedilol of about 5 [63]. Dual mechanism of action includes selective beta1-receptor blockade and stimulation of endothelial NO production [62]. Additionally, B1-specific BAR-blockers can block renal $B 1$-adrenergic receptors and concomitant renin

Table 2 Summarizes the hypothetical aim of therapy and the used heart failure drugs

1. Heart rate control in order to improve the ratio of (myocardial) oxygen consumption to demand and prolong the time for diastolic ventricular filling ( $(1$-specific $ß$-blocker)

2. Diminishing apoptosis and myocytes necrosis (ß1-specific ß-blocker)

3. Diminishing interstitial fibrosis by blocking sympathetic- and RAA-S (three first-line drugs)

4. Reduction of cardiac afterload together with preservation of the coronary perfusion pressure by adequate (preload) intravascular, in particular, arterial vascular filling (avoidance of diuretics, effectively dosed ACE-I $+\beta 1$-specific blocker, preserving the beta 2 receptor function)

5. Basis for additional strategies to re-establish ventricular synchrony and re-establish VVI as prerequisite for cardiac regeneration (all three firstline drugs)

6. Low risk-benefit ratio and high parental compliance by daily singledose therapy together with easy dosing of $0.1-0.2(0.3) \mathrm{mg} / \mathrm{kg} \times$ day for both bisoprolol and lisinopril and once application of spironolactone $1-2 \mathrm{mg} / \mathrm{kg} \times$ day, respectively 
release caused by HF or in association with ACE inhibitor therapy [10].

Combined with $\beta 1$-adrenoreceptor blockers, long-acting tissue angiotensin-converting enzyme inhibitors [57] like lisinopril or ramipril are our age-independent HF drugs of choice, based on the hypothesis that stimulated RAAS can be blocked by both drugs acting synergistically to lower systemic vascular resistance and avoid myocardial fibrosis, the latter together with the mineralocorticoid-receptor blocker spironolactone.

In order to improve systemic blood flow, these drugs have not only been recommended in HF patients with stable hemodynamics [25], but also to transit unstable patients to a stable hemodynamic status [43, 50, 53]. More recently, we are treating all LV-DCM patients with the triple drug combination in preparation for reversible pulmonary artery banding [43, 53]. Only patients with volume depletion due to overdiuresis are excluded, but ongoing inotropic support is not a contraindication for additional $ß 1$-adrenoreceptor blockade, which may facilitate successful weaning of inotropes. Clinical parameters and biomarkers monitor treatment success (Fig. 3). Treatment compliance together with very low side effects, can be impressive, as we could observe and document prior to and immediately after reversible pulmonary arterial banding (rPAB) as a novel therapy to treat LV-DCM [43, 53].

Additional questions arise: why is captopril typically recommended as the first choice for HF treatment in infants and enalapril an appropriate choice for those older than the age of 2 years [24]? In infants and young children, bronchoconstriction and bronchiolitis are common and often associated with HF. Thus, it is our view that non-specific BAR blockers with a 32 -blocking effect and less-specific ACE-I with a higher risk of bradykinin-dependent cough and bronchoconstriction should be avoided. High renin and creatinin levels together with hyponatremia are classical signs not only of severe HF but also of inadequate diuretic therapy. To lower the risk of a blood pressure drop after initiating vasodilator therapy, there should not be a dosage reduction or withdrawal of ACE-I therapy, but rather implementation of diuretics [19, 20, 37, 44, 59].

\section{Hyperdynamic HF related to a ventricular left-to-right shunt}

Surgical or transcatheter closure of a hemodynamically relevant ventricle septum defect (VSD) is the treatment of choice. However, there may be several reasons why such a curative approach cannot be performed or need to be delayed. Diuretics, digoxin, and fluid restriction are usually recommended to treat chronic HF based on a left-right shunt, although there is no data that document efficacy $[12,15,42$, 55]. This above management strategy is ill conceived because diuretics, fluid restriction, and digoxin do not achieve the goal of increasing systemic blood flow but instead favor the imbalance of pulmonary and systemic blood flow [12, 13]. Diureticand fluid restriction-dependent neuro-humoral stimulation and digoxin-caused vasoconstriction increase the left-right

\section{$L V-D C M+p R V-E F$ : BNP-values ad admission and prior to rPAB}

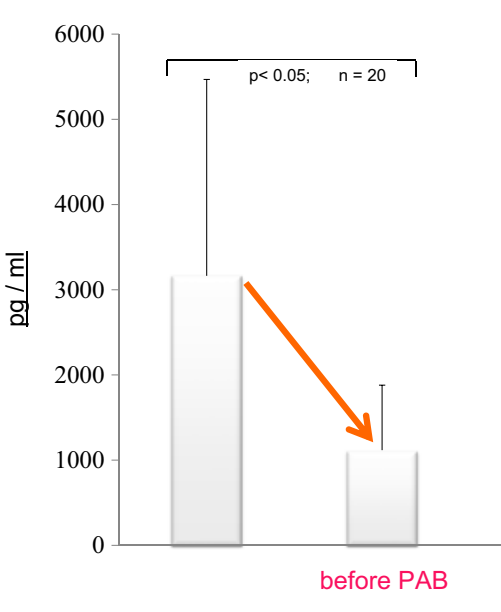

Fig. 3 Shown is the mean brain natriuretic peptide (BNP) value of 20 infants and children younger than 3 years with left ventricular dilative cardiomyopathy (LV-DCM) and preserved right ventricular ejection fraction (pRV-EF), which were admitted for heart transplantation. The extremely high BNP values at admission decreased significantly [we believe as a consequence of the administered 'triple therapy'] during the period prior to surgical pulmonary banding (PAB). At admission, all "up-graded HF-Therapy"

continuous Milrinone/Levosimendane

Cessation of Furosemide

Start with Bisoprolol / HR $<120 / \mathrm{min}$

with Lisinopril

with Spironolactone

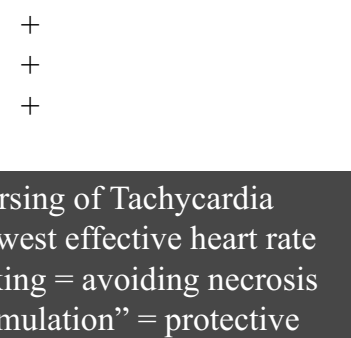

patients had been treated with in some high dosages of furosemide independent of continuously administered inotropic treatment. Furosemide was stopped and bisoprolol (B), lisionopril (L), and spironolactone (S) were started. The goal was to achieve a resting heart rate (HR) of less than $120 /$ min with an adequate systemic blood pressure to sufficient diuresis. The inotropic treatment was continued, but if dobutamine had been part of the pre-admission regiment, it was changed to the inodilator milrinone 
Fig. 4 Represents L/R shunt of hemodynamically relevant VSD; infants and young children not early surgically corrected, but mid-term treated by diuretics and fluid restriction develop as pictured severe cachexia because L/ $\mathrm{R}$ shunt is favored by increased systemic vascular resistance and high oxygen consumption by compensating increased heart and breath rate and in particular of malnutrition

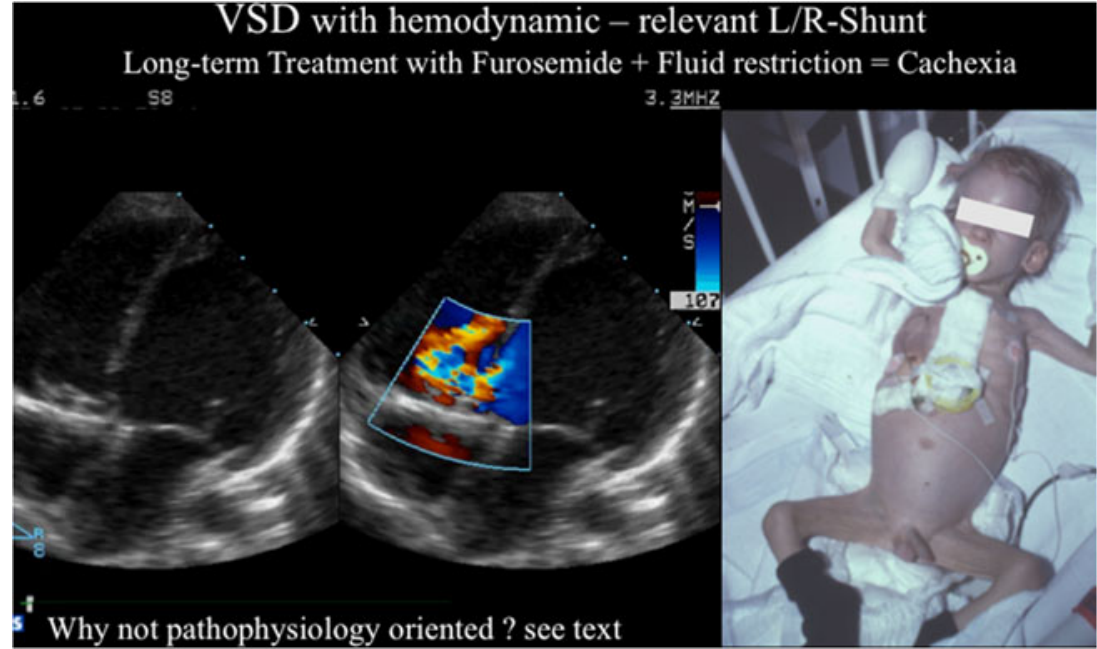

shunt; in mid-term, such treatment might be associated by cardiac cachexia (Fig. 4). And as a reminder, in congenital heart defects with left-right shunt, the systolic function of the left ventricle is mostly preserved [13], whereas diastolic function may be impaired. Older patients with a left-right shunt develop commonly diastolic dysfunction caused by the compensatory mechanism of left ventricular volume depletion due to sympathetic and RAA stimulation. Again, based on our own institutional experience of more than a decade, bisoprolol without blocking the systemic vasodilation favoring 32-adrenoreceptor, highly specific tissue ACE-I, like lisinopril and spironolactone, if diastolic dysfunction with preserved ejection fraction are present, should be and are used to influence the balance of left-to-right shunt in order to favor systemic blood flow. The improvement of chronic HF symptoms can be easily monitored by the decrease in heart and

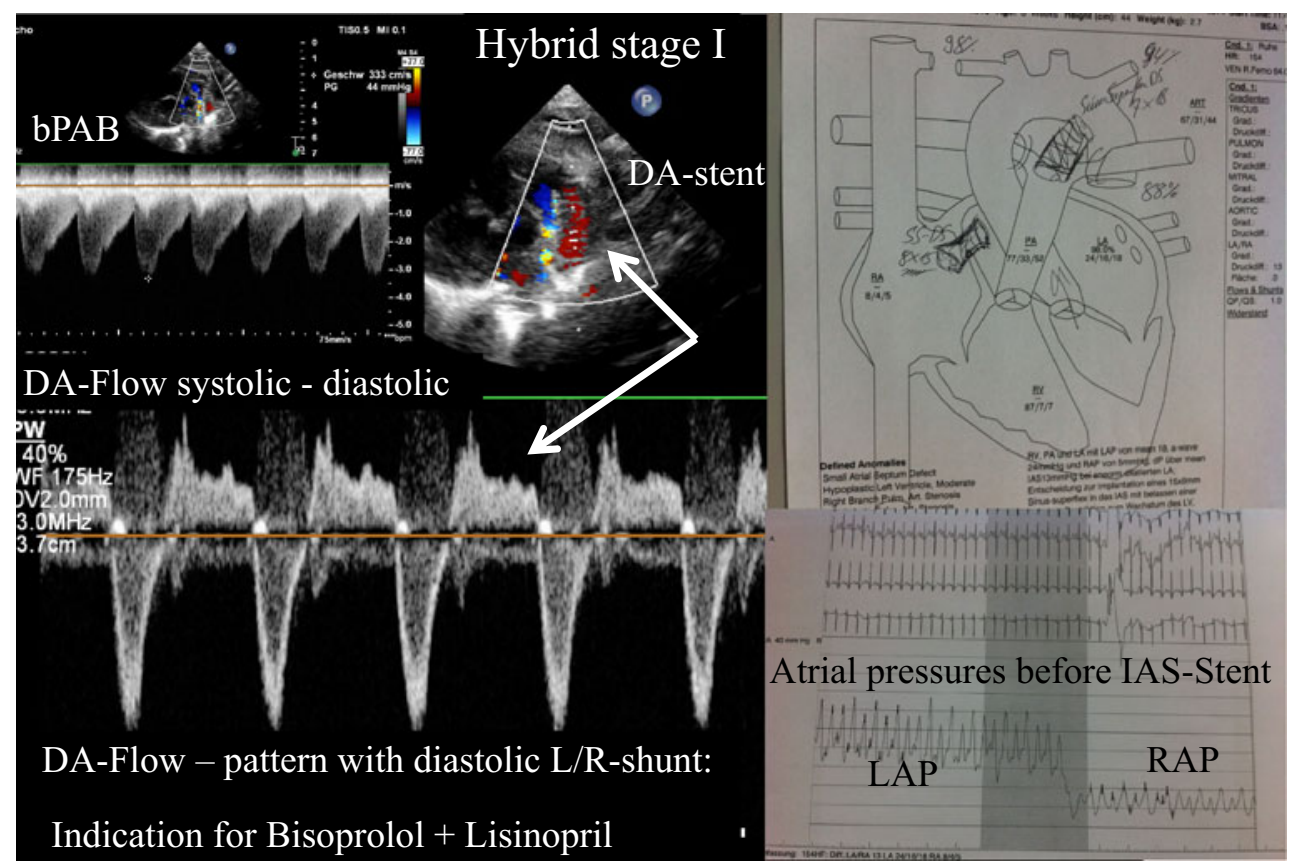

Fig. 5 Shows the schematic picture of Hybrid stage I consisting of duct stenting (DA stent), bilateral pulmonary banding $(b P A B)$, and interatrial septum manipulation by stent placement. Left atrial $(L A P)$ decompression to a pressure level of the right atrium $(R A P)$ is an important part of a balanced parallel turned pulmonary to systemic circulation. The echocardiography shows an effective bPAB by its typical flow-pattern, but despite an effective $\mathrm{BPAB}$, the systolic right-to-left flow through the duct is accompanied by a diastolic left-to-right reflow; one important indication to reduce the systemic vascular resistance without jeopardizing coronary blood flow. Additionally, bisoprolol reduces heart rate, which improves single ventricle filling; all factors together diminish pulmonary congestion, reduce total and myocardial oxygen consumption, and improve the baby's functional class 
respiratory rates, signs of less severe pulmonary congestion, and improved food intake in infants. This therapeutic concept avoids cardiac cachexia, which was usually observed in almost all patients in the past and is still observable today.

\section{HF prophylaxis in hypoplastic left heart syndrome after hybrid stage I}

The right ventricle as the systemic heart chamber is usually found in congenital malformations like congenital corrected transposition of the great arteries (ccTGA) and also in the hypoplastic left heart syndrome (HLHS) and in the HLHcomplex; in HLHC, the right ventricle works in parallel with an obstructed or borderline left ventricle. There is growing evidence that RV dysfunction develops in many of those patients and accounts for the considerable morbidity and mortality. Therefore, systemic RV function needs close surveillance and sufficient timing of an appropriate intervention to optimize outcome. Almost dogmatically, HF medications, which have been pronounced to be effective for the treatment of a failing left ventricle, are judged to be ineffective for treating a failing systemic right ventricle [24, 25]. However, we wish to point out that the subpulmonary right or left ventricle is metabolically differently active and this may have substantial implications for the pharmacotherapy. Genes encoding drug-metabolizing enzymes, like cytochrome P450 mono-oxygenases, are predominantly expressed in the subpulmonary heart chamber; this might explain the lack of efficacy of drugs like angiotensinconverting enzyme inhibitors and angiotensin receptor blockers on a subpulmonary RV or LV. An atrial switch of the venous connection to the right and left atria reverses the messenger RNA expression profiles. An anatomical left, but subpulmonary positioned, ventricle shows the expression of cytochrome P450 genes normally found in the subpulmonary RV. These facts highlight the importance of the subpulmonary ventricle and pulmonary circulation for the metabolic breakdown of drugs [58]. Thus, for the pharmacological response more important than the morphology of the ventricle appears to be its position. Such data are not available for univentricular hearts, in particular prior to Fontan completion. Considering HLHS, the right ventricle is responsible for the systemic and pulmonary circulation, but following the surgical completion of the Fontan circulation, the distally to the pulmonary circulation positioned RV supports the systemic circulation.

At our institution, neonates born with HLHS and some patients with HLHC are palliated using the Giessen Hybrid approach which consists of bilateral pulmonary banding, duct stenting, and, if necessary, atrial septum manipulation (Fig. 5). This approach has been established more than 17 years ago as an alternative to the Norwood stage I operation [54]. It is our goal to reduce inter-stage morbidity and mortality; one part of this inter-stage strategy is based on the use of dual or triple therapy of bisoprolol with lisinopril and spironolactone. The use of $\beta 1$-selective BAR blockers is further supported by recently published data from Miyamoto et al. [34], which stresses the altered BAR signaling in HLHS [34]. During the last 5 years, we have routinely avoided diuretics or digoxin when treating newborns or young infants discharged home after the hybrid procedure. We monitor heart and respiratory rate (Video 1) and, intermittently, systolic and diastolic blood pressure. The mean blood pressure should not be relied on simply because a diminished systemic blood flow might remain undetected. Echocardiographic and serum biomarkers (BNP, ProBNP) ought to be used for additional, intermittent monitoring. The blood pressure amplitude, together with the echocardiographically estimated degree of diastolic left-toright shunt across the stented duct is important and supports our medical strategy (Fig. 5). The effect of the drug therapy on the systemic vascular resistance can be easily monitored. Low heart rate, prolonged diastolic filling time, and reduction of systemic vascular resistance (without increasing retrograde aortic blood flow and jeopardizing myocardial perfusion pressure) are the therapeutic goals. Excellent parental compliance with a single-dose regiment and the monitoring of body weight prior to hybrid stage II are usually obtained. Whether out-of-proportion myocardial hypertrophy of the systemic right ventricle or interstitial fibrosis can also be reduced by our treatment strategy remains to be examined in future studies.

\section{In conclusion}

Our clinical practice and institutional experience in chronic HF treatment in infants and children with left ventricular systolic heart failure, high-output failure due to significant left-right shunting congenital heart diseases, as well as HLHS and HLH-complex after hybrid stage I, are in clear contrast to the official guidelines for chronic HF therapy in infants and children. We acknowledge as a substantial weakness that we are missing randomized study results; however, in the absence of such trials, observational studies should receive credit as a first step. In addition, the here illustrated chronic HF therapy can lay the ground for a randomized multicenter studies designed to analyze the efficacy of other endogenous repair mechanisms supporting therapies as we advocated by pulmonary arterial banding in selected young patients with DCM and preserved right ventricular function.

Authors' contributions Dietmar Schranz conceptualized and drafted the initial manuscript and approved the final manuscript. Norbert Voelkel critically reviewed, revised, and approved the final manuscript as submitted.

Compliance with ethical standards This article does not contain any studies with human participants performed by any of the authors. 
Conflict of interest The authors declare that they have no competing interests.

Open Access This article is distributed under the terms of the Creative Commons Attribution 4.0 International License (http:// creativecommons.org/licenses/by/4.0/), which permits unrestricted use, distribution, and reproduction in any medium, provided you give appropriate credit to the original author(s) and the source, provide a link to the Creative Commons license, and indicate if changes were made.

\section{References}

1. (1987) Effects of enalapril on mortality in severe congestive heart failure. Results of the Cooperative North Scandinavian Enalapril Survival Study (CONSENSUS). The aldosterone CONSENSUS Trial Study Group. N Engl J Med 316:1429-1435

2. (1999) Effect of metoprolol CR/XL in chronic heart failure: metoprolol CR/XL Randomized Intervention Trial in Congestive Heart Failure (MERIT-HF). Lancet 353:2001-2007

3. (1999) The Cardiac Insufficiency Bisoprolol Study II (CIBIS-II): a randomized trial. Lancet 353: 9-13

4. Ahmet I, Krawczyk M, Heller P, Moon C, Lakatta EG, Talan MI (2004) Beneficial effects of chronic pharmacological manipulation of beta-adrenoreceptor subtype signaling in rodent dilated ischemic cardiomyopathy. Circulation 110:1083-1090

5. Ahmet I, Krawczyk M, Zhu W, Woo AY, Morrell C, Poosala S, Xiao RP, Lakatta EG, Talan MI (2008) Cardioprotective and survival benefits of long-term combined therapy with beta2 adrenoreceptor (AR) agonist and beta1 AR blocker in dilated cardiomyopathy postmyocardial infarction. J Pharmacol Exp Ther 325:491-499

6. Arola A, Tuominen J, Ruuskanen O, Jokinen E (1998) Idiopathic dilated cardiomyopathy in children: prognostic indicators and outcome. Pediatrics 101:369-376

7. Bergmann O, Bhardwaj RD, Bernard S, Zdunek S, Barnabe-Heider F, Walsh S, Zupicich J, Alkass K, Buchholz BA, Druid H, Jovinge S, Frisen J (2009) Evidence for cardiomyocyte renewal in humans. Science 324:98-102

8. Bernstein D, Fajardo G, Zhao M (2011) The role of ß-adrenergic receptors in heart failure: differential regulation of cardiotoxicity and cardioprotection. Prog Pediatr Cardiol 31(1):35-38

9. Bhushan S, Kondo K, Predmore BL, Zlatopolsky M, King AL, Pearce C, Huang H, Tao YX, Condit ME, Lefer DJ (2012) Selective beta2-adrenoreceptor stimulation attenuates myocardial cell death and preserves cardiac function after ischemiareperfusion injury. Arterioscler Thromb Vasc Biol 32:1865-1874

10. Blair ML, Woolf PD, Felten SY (1997) Sympathetic activation cannot fully account for increased plasma renin levels during water deprivation. Am J Physiol 272:R1197-R1203

11. Brodde O-E (1991) Beta 1- and beta 2-adrenoceptors in the human heart: properties, function, and alterations in chronic heart failure. Pharmacol Rev 43:203-242

12. Buchhorn R, Ross RD, Bartmus D, Wessel A, Hulpke-Wette M, Bürsch J (2001) Activity of the renin-angiotensin-aldosterone and sympathetic nervous system and their relation to hemodynamic and clinical abnormalities in infants with left-to-right shunts. Int $\mathrm{J}$ Cardiol 78(3):225-230, discussion 230-1

13. Buchhorn R, Hulpke-Wette M, Hilgers R, Bartmus D, Wessel A, Bürsch J (2001) Propranolol treatment of congestive heart failure in infants with congenital heart disease: the CHF-PRO-INFANT Trial.
Congestive heart failure in infants treated with propanol. Int $\mathrm{J}$ Cardiol 79(2-3):167-173

14. Digitalis Investigation Group (DIG) (1997) The effect of digoxin in mortality and morbidity in patients with heart failure. N Engl J Med 306:525-533

15. Elkiran O, Sandikkaya A, Kocak G, Karakurt C, Taskapan C, Yologlu S (2013) Evaluation by N-terminal prohormone of brain natriuretic peptide concentrations and Ross scoring of the efficacy of digoxin in the treatment of heart failure secondary to congenital heart disease with left-to-right shunts. Pediatr Cardiol 34:15831589

16. Engle MA, Lewy JE, Lewy, Metcoff J (1978) The use of furosemide in the treatment of edema in infants and children. Pediatrics 62:811-818

17. Fajardo G, Zhao M, Berry G, Wong LJ, Mochly-Rosen D, Bernstein D (2011) Beta2-Adrenergic receptors mediate cardioprotection through crosstalk with mitochondrial cell death pathways. J Mol Cell Cardiol 51:781-789

18. Faris RF, Flather M, Purcell H, Poole-Wilson PA, Coats AJ (2012) Diuretics for heart failure. Cochrane Database Syst Rev CD003838

19. Gheorghiade M, Niazi I, Ouyang J, Czerwiec F, Kambayashi J, Zampino M, Orlandi C (2003) Clinical investigation and reports vasopressin $\mathrm{V}_{2}$-receptor blockade with tolvaptan in patients with chronic heart failure. Results from a double-blind. Randomized Trial Circ 107:2690-2696

20. Hirano D, Kakegawa D, Yamada A, Ito A, Miwa S, Ida H (2015) Tolvaptan in a pediatric patient with diuretic-resistant heart and kidney failure. Pediatr Int 57(1):183-185

21. Hsu DT, Pearson GD (2009) Heart failure in children. Part I: history, etiology, and pathophysiology. Circ Heart Fail 2:63-70

22. Hsu DT, Pearson GD (2009) Part II: diagnosis, treatment, and future directions. Circ Heart Fail 2:490-498

23. Hsu DT, Zak V, Mahony L, Sleeper LA, Atz AM, Levine JC, Barker PC, Ravishankar C, McCrindle BW, Williams RV, Altmann K, Ghanayem NS, Margossian R, Chung WK, Border WL, Pearson GD, Stylianou MP, Mital S (2010) Enalapril in infants with single ventricle. Results of a multicenter randomized trial. Circulation 122:333-340

24. Jain S, Vaidyanathan B (2009) Digoxin in management of heart failure in children: should it be continued or relegated to the history books? Ann Pediatr Cardiol 2:149-152

25. Kantor PF, Lougheed J, Dancea A, McGillion M, Barbosa N, Chan C, Dillenburg R, Atallah J, Buchholz H, Chant-Gambacort C, Conway J, Gardin L, George K, Greenway S, Human DG, Jeewa A, Price JF, Ross RD, Roche SL, Ryerson L, Soni R, Wilson J, Wong K et al (2013) Presentation, diagnosis, and medical management of heart failure in children: Canadian cardiovascular society guidelines. Can J Cardiol 29:1535-1552

26. Latus H, Schranz D, Apitz C (2015) Treatment of pulmonary arterial hypertension in children. Nat Rev Cardiol 12(4):244-254

27. Lipshultz SE, Sleeper LA, Towbin JA, Lowe AM, Orav EJ, Cox GF, Lurie PR, McCoy KL, McDonald MA, Messere JE, Colan SD (2003) The incidence of pediatric cardiomyopathy in two regions of the United States. N Engl J Med 348:1647-1655

28. Masutani S, Saiki H, Kurishima C, Ishido H, Tamura M, Senzaki H (2013) Heart failure with preserved ejection fraction in children. Hormonal imbalance between aldosterone and brain natriuretic peptide. Circ J 77:2375-2382

29. McMurray JJV, Adamopoulos S, Anker SD Adamopoulos S, Anker SD, Auricchio A, Böhm M, Dickstein K, Falk V, Filippatos G, Fonseca C, Gomez-Sanchez MA, Jaarsma T, Køber L, Lip GY, Maggioni AP, Parkhomenko A, Pieske BM, Popescu BA, Rønnevik PK, Rutten FH, Schwitter J, Seferovic P, Stepinska J, Trindade PT, Voors AA, Zannad F, Zeiher A, Task Force for the Diagnosis and Treatment of Acute and Chronic Heart Failure 2012 of the European Society of Cardiology, Bax JJ, Baumgartner H, 
Ceconi C, Dean V, Deaton C, Fagard R, Funck-Brentano C, Hasdai D, Hoes A, Kirchhof P, Knuuti J, Kolh P, McDonagh T, Moulin C, Popescu BA, Reiner Z, Sechtem U, Sirnes PA, Tendera M, Torbicki A, Vahanian A, Windecker S, McDonagh T, Sechtem U, Bonet LA, Avraamides P, Ben Lamin HA, Brignole M, Coca A, Cowburn P, Dargie H, Elliott P, Flachskampf FA, Guida GF, Hardman S, Iung B, Merkely B, Mueller C, Nanas JN, Nielsen OW, Orn S, Parissis JT, Ponikowski P (2012) ESC Guidelines for the diagnosis and treatment of acute and chronic heart failure 2012. The Task force for the Diagnosis and Treatment of Acute and Chronic Heart Failure 2012 of the European Society of Cardiology. Eur Heart J 33:17871847

30. McMurray JJV, Packer M, Desai AS, Gong J, Lefkowitz MP, Rizkala AR, Rouleau JL, Shi VC, Solomon SD, Swedberg K, Zile MR (2014) Angiotensin-neprilysin inhibition versus enalapril in heart failure. N Engl J Med 371:993-1004

31. Milavec-Krizman M, Evenou JP, Wagner H, Berthold R, Stoll AP (1985) Characterization of beta-adrenoceptor subtypes in rat kidney with new highly selective beta 1 blockers and their role in renin release. Biochem Pharmacol 34:3951-3957

32. Ming Z, Parent R, Lavallée M (1997) $\beta_{2}$-Adrenergic dilation of resistance coronary vessels involves $\mathrm{K}_{\mathrm{ATP}}$ channels and nitric oxide in conscious dogs. Circulation 95:1568-1576

33. Miyamoto SD, Stauffer BL, Nakano S, Sobus R, Nunley K, Nelson P, Sucharov CC (2014) Beta-adrenergic adaptation in paediatric idiopathic dilated cardiomyopathy. Eur Heart J 35:33-41

34. Miyamoto SD, Stauffer BL, Polk J, Medway A, Friedrich M, Haubold K, Peterson V, Nunley K, Nelson P, Sobus R, Stenmark KR, Sucharov CC (2014) Gene expression and $\beta$-adrenergic signaling are altered in hypoplastic left heart syndrome. J Heart Lung Transplant 33(8):785-793

35. Motonaga KS, Dubin AM (2014) Cardiac resynchronization therapy for pediatric patients with heart failure and congenital heart disease: a reappraisal of results. Circulation 129:1879-1891

36. Mozaffarian D, Benjamin EJ, Go AS, Benjamin EJ, Go AS, Arnett DK, Blaha MJ, Cushman M, de Ferranti S, Després JP, Fullerton HJ, Howard VJ, Huffman MD, Judd SE, Kissela BM, Lackland DT, Lichtman JH, Lisabeth LD, Liu S, Mackey RH, Matchar DB, McGuire DK, Mohler ER 3rd, Moy CS, Muntner P, Mussolino ME, Nasir K, Neumar RW, Nichol G, Palaniappan L, Pandey DK, Reeves MJ, Rodriguez CJ, Sorlie PD, Stein J, Towfighi A, Turan TN, Virani SS, Willey JZ, Woo D, Yeh RW, Turner MB (2015) Heart disease and stroke statistics 2015 update: a report from the American Heart Association. Circulation 131:e29-e322

37. Murakami T, Horibata Y, Morimoto Y, Tateno S, Kawasoe Y, Niwa K (2013) Syndrome of inappropriate secretion of antidiuretic hormone associated with angiotensin-converting enzyme inhibitor administration. Pediatr Cardiol 34(5):1261-1263

38. Navaratnarajah M, Siedlecka U, Ibrahim M, van Doorn C, Soppa G, Gandhi A, Shah A, Kukadia P, Yacoub MH, Terracciano CM (2014) Impact of combined clenbuterol and metoprolol therapy on reverse remodelling during mechanical unloading. PLoS One 9(9). Published online Sep 30, 2014

39. Nugent AW, Daubeney PE, Chondros P, Carlin JB, Cheung M, Wilkinson LC, Davis AM, Kahler SG, Chow CW, Wilkinson JL, Weintraub RG (2003) The epidemiology of childhood cardiomyopathy in Australia. N Engl J Med 348:1639-1646

40. Packer M, Coats AJ, Fowler MB, Katus HA, Krum H, Mohacsi P, Rouleau JL, Tendera M, Castaigne A, Roecker EB, Schultz MK, DeMets DL (2001) Effect of carvedilol on survival in severe chronic heart failure. N Engl J Med 344:1651-1658

41. Pitt B, Zannad F, Remme WJ, Cody R, Castaigne A, Perez A, Palensky J, Wittes J (1999) The effect of spironolactone on morbidity and mortality in patients with severe heart failure. $\mathrm{N}$ Engl $\mathrm{J}$ Med 341:709-717
42. Rathore SS, Curtis JP, Wang Y, Bristow MR, Krumholz HM (2003) Association of serum digoxin concentration and outcomes in patients with heart failure. JAMA 289:871-878

43. Recla S, Steinbrenner B, Schranz D (2013) Medical therapy in dilated cardiomyopathy and pulmonary arterial banding in children. J Heart Lung Transplant 32:1045-1046

44. Regen RB, Gonzalez A, Zawodniak K, Leonard D, Quigley R, Barnes AP, Koch JD (2013) Tolvaptan increases serum sodium in pediatric patients with heart failure. Pediatr Cardiol 34(6):1463-1468

45. Rinaldi B, Donniacuo M, Sodano L. Effects of the new ultra-longacting $\beta_{2}-\mathrm{AR}$ agonist indacaterol in chronic treatment alone or in combination with the $\beta_{1}$-AR blocker metoprolol on cardiac remodeling. Br J Pharmacol in press

46. Rodeheffer RJ, Jacobsen SJ, Gersh BJ, Kottke TE, McCann HA, Bailey KR, Ballard DJ (1993) The incidence and prevalence of congestive heart failure in Rochester, Minnesota. Mayo Clin Proc 68:1143-1150

47. Ross RD, Daniels SR, Schwartz DC, Hannon DW, Shukla R, Kaplan S (1987) Plasma norepinephrine levels in infants and children with congestive heart failure. Am J Cardiol 59:911-914

48. Rossano JW MD, Shaddy RE (2014) Update on pharmacological heart failure therapies in children. Do adult medications work in children and if not, why not? Circulation 129:607-612

49. Rossano JW. Medical therapy of pediatric heart failure: what have we learned in the last 10 years? | Expert Analysis. JACC; Apr 07, 2015, see more at: http://www.acc.org/latest-in-cardiology/articles/ 2015/04/06/11/41/medical-therapy-of-pediatric-heart-failure?

50. Rupp S, Apitz C, Tholen L, Latus H, Ostermayer SH, Schmidt D, Bauer J, Schranz D et al (2014) Upgraded heart failure therapy leads to an improved outcome of dilated cardiomyopathy in infants and toddlers. Cardiol Young 12:1-6

51. Schmaltz AA (2015) Chronic congestive heart failure in infancy and childhood. New aspects of diagnosis and treatment. Klin Padiatr 227:3-9

52. Schranz D, Droege A, Broede A, Brodermann G, Schafer E, Oelert H, Brodde OE (1993) Uncoupling of human cardiac adrenoceptors during cardiopulmonary bypass with cardioplegic cardiac arrest. Circulation 87:422-426

53. Schranz D, Rupp S, Müller M, Schmidt D, Bauer A, Valeske K, Michel-Behnke I, Jux C, Apitz C, Thul J, Hsu D, Akintürk H (2013) Pulmonary artery banding in infants and young children with left ventricular dilated cardiomyopathy: a novel therapeutic strategy before heart transplantation. J Heart Lung Transplant 32:475-481

54. Schranz D, Bauer A, Reich B, Steinbrenner B, Recla S, Schmidt D, Apitz C, Thul J, Valeske K, Bauer J, Müller M, Jux C, Michel-Behnke I, Akintürk H (2015) Fifteen-year single center experience with the "Giessen Hybrid" approach for hypoplastic left heart and variants: current strategies and outcomes. Pediatr Cardiol 36(2):365-373

55. Seguchi M, Nakazawa M, Momma K (1999) Further evidence suggesting a limited role of digitalis in infants with circulatory congestion secondary to large ventricular septal defect. Am J Cardiol 83: $1408-1411$

56. Shaddy RE, Boucek MM, Hsu DT, Boucek RJ, Canter CE, Mahony L, Ross RD, Pahl E, Blume ED, Dodd DA, Rosenthal DN, Burr J, LaSalle B, Holubkov R, Lukas MA, Tani LY (2007) Carvedilol for children and adolescents with heart failure: a randomized controlled trial. JAMA 298:1171-1179

57. Shah AD, Arora RR (2005) Tissue angiotensin-converting enzyme inhibitors: are they more effective than serum angiotensinconverting enzyme inhibitors? Clin Cardiol 28(12):551-555

58. Thum T, Borlak J (2000) Gene expression in distinct regions of the heart. Lancet 355(9208):979-983

59. Tominaga N, Kida K, Matsumoto N, Akashi YJ, Miyake F, Kimura K, Shibagaki Y (2015) Safety of add-on tolvaptan in patients with furosemide-resistant congestive heart failure complicated by advanced 
chronic kidney disease: a sub-analysis of a pharmacokinetics/ pharmacodynamics study. Clin Nephrol 84(7):29-38

60. Towbin JA, Lowe AM, Colan SD, Sleeper LA, Orav EJ, Clunie S, Messere J, Cox GF, Lurie PR, Hsu D, Canter C, Wilkinson JD, Lipshultz SE (2006) Incidence, causes, and outcomes of dilated cardiomyopathy in children. JAMA 296:1867-1876

61. Voelkel N, Schranz D (2015) The right ventricle in health and disease. Springer
62. Volpe M, Tocci G, Pagannone E (2006) Fewer mega-trials and more clinically oriented studies in hypertension research? The case of blocking the renin- angiotensin-aldosterone system. J Am Soc Nephrol 17:S36-S43

63. Xiao RP, Zhu W, Zheng M, Chakir K, Bond R, Lakatta EG, Cheng H (2004) Subtype-specific beta-adrenoceptor signaling pathways in the heart and their potential clinical implications. Trends Pharmacol Sci 25(7):358-365 